\title{
Skin cancer in the elderly - epidemiological, clinical and surgical treatment analysis of 254 patients
}

\author{
Michał Sobjanek ${ }^{1}$, Igor Michajłowski ${ }^{1}$, Marta Malek$^{1}$, Monika Zabłotna ${ }^{1}$, Adam Włodarkiewicz $^{2}$, Roman Nowicki ${ }^{1}$
}

1Department of Dermatology, Venereology and Allergology, Medical University of Gdansk, Poland Head: Prof. Roman Nowicki MD, PhD

2Department of Oral and Maxillofacial Surgery, Medical University of Gdansk, Poland

Head: Prof. Adam Włodarkiewicz MD, DDS, PhD

\begin{abstract}
Introduction: The incidence of non-melanoma skin cancer (NMSC) and melanoma is increasing rapidly in the European population. There are only a few reports about cutaneous malignancy in the elderly population.

Aim: Epidemiological, clinical, histopathological and surgical treatment result analysis of skin cancers in patients over 75 years old.

Material and methods: A group of 254 patients over 75 years old operated on during 2002-2006 in the Department of Dermatology, Venerology and Allergology of the Medical University of Gdansk was included in the study. Sex ratio F/M was 1.2. The average age was 81.1 years old.

Results: Patients over 75 years old comprised $40 \%$ of all operated patients because of malignancy in the analyzed period. Non-melanoma skin cancer were diagnosed in $92.5 \%$ of cases, melanoma in $5.9 \%$. Basal cell carcinoma (BCC) was the most common malignancy, diagnosed in $72 \%$ of the patients. The incidence of squamous cell carcinoma (SCC) was statistically significantly higher compared to the general population ( $20.5 \%$ vs. $10.9 \% ; p=0.0002)$. BCC/SCC ratio was 3.5. In 39 patients (16.6\%) multiple NMSC were observed. Exposure to UV radiation was the most common (52\%) risk factor of cutaneous malignancy. The local recurrence rate of NMSC was $5.51 \%$.

Conclusions: The incidence of skin cancers in the northern Polish population over 75 years old is increasing. The clinical and histopathological profile of skin cancer in the elderly differs from the general population. Surgical treatment is safe and effective management in these cases.
\end{abstract}

Key words: skin malignancy, advanced aged patients, surgical treatment.

\section{Introduction}

Aging of the European population has been observed for the last few decades, caused by longer life span and decrease of population growth rate. This tendency is noted also in Poland. According to the Central Statistical Office in 1963 people aged over 65 years comprised $6.4 \%$ of the population, in 2005 13.3\%. It is estimated than in 2030 it will reach about $24 \%$.

The overall incidence of skin cancer (non-melanoma skin cancer (NMSC) and melanoma) is increasing rapidly [1-3]. These two facts are the reason why more and more skin cancers are noted in the elderly.

In the worldwide literature, there are only a few reports about geriatric patients with skin cancer, while in Polish literature such reports have not been found.
Aim

Epidemiological, clinical, histopathological and surgical treatment analysis of skin cancers in patients over 75 years old, operated on in the Department of Dermatology, Venereology and Allergology of the Medical University of Gdansk.

\section{Material and methods}

We retrospectively analyzed the clinical cases of patients operated on in the Department of Dermatology between 2002 and 2006 because of skin malignancy. Two hundred and fifty-four patients over 75 years old were found, including 14 over 90 years old (138 women and 116 men (sex ratio F/M 1.2)). The average age of the patients

Address for correspondence: Michał Sobjanek MD, PhD, Department of Dermatology, Venereology and Allergology, Medical University of Gdansk, 7 Dębinki St, 80-952 Gdansk, Poland, phone: +48 607039 729, e-mail: sobjanek@wp.pl 
was 81.13 years. Risk factors, localization, clinical and histological type of tumor and recurrence rate were analyzed.

Most of the patients (98.4\%) were treated using local anesthesia. Tumors were excised with the standard onco-

Table 1. Characteristics of patients

\begin{tabular}{|c|c|}
\hline Parameter & $n(\%)$ \\
\hline \multicolumn{2}{|l|}{ Sex: } \\
\hline Female & $138(54.3)$ \\
\hline Male & $116(45.7)$ \\
\hline Overall group & $254(100)$ \\
\hline \multicolumn{2}{|l|}{ Histopathological diagnosis: } \\
\hline $\mathrm{BCC}$ & $183(72)$ \\
\hline SCC & $52(20.5)$ \\
\hline Melanoma & $15(5.9)$ \\
\hline Merkel cell carcinoma & $2(0.8)$ \\
\hline Fibrosarcoma & $2(0.8)$ \\
\hline Overall group & $254(100)$ \\
\hline \multicolumn{2}{|l|}{ Tumor site: } \\
\hline Head and neck & $194(76.4)$ \\
\hline Lower limbs & $20(7.9)$ \\
\hline Upper limbs & $15(5.9)$ \\
\hline Trunk & $25(9.8)$ \\
\hline Overall group & $254(100)$ \\
\hline \multicolumn{2}{|l|}{ Skin phototype (according to Fitzpatrick): } \\
\hline I & $10(3.9)$ \\
\hline ॥ & $127(50)$ \\
\hline III & $97(38.2)$ \\
\hline IV & $20(7.9)$ \\
\hline Overall group & $254(100)$ \\
\hline \multicolumn{2}{|l|}{ Risk factors: } \\
\hline Chronic exposure to UV & $132(52)$ \\
\hline Burns of the skin & $72(28.3)$ \\
\hline Family or personal history of skin cancer & $22(8.66)$ \\
\hline Fair skin phototype (I and II) & $137(53.9)$ \\
\hline \multicolumn{2}{|l|}{ Staging of NMSC: } \\
\hline $\mathrm{T} 1$ & $159(67.7)$ \\
\hline $\mathrm{T} 2$ & 40 (17.0) \\
\hline T3 & $16(6.8)$ \\
\hline T4 & $16(6.8)$ \\
\hline Overall group & $235(100)$ \\
\hline
\end{tabular}

logical margin. Sixteen patients were operated on due to cancer reoccurrence after cryodestruction (8 cases), radiotherapy (4) and resection (4). The reconstruction was always performed immediately after the tumor's excision, in the majority of cases using the simplest method of closing the tissue. In 12 cases surgical treatment was combined with radiotherapy. Follow-up was performed 6 to 10 years post surgery and included 171 patients (67.32\%). Results were statistically analyzed using $\chi^{2}$ test with Yates' correction and compared with the whole treated group [4].

\section{Results}

Patients over 75 years old comprised $40 \%$ of all operated patients because of cutaneous malignancy in the analyzed period. A statistically significant increase in the number of patients over 75 years old was noted ( $p=0.0003$ ). Table 1 shows characteristics of the patients. Nonmelanoma skin cancer were diagnosed in $92.5 \%$ of cases. Basal cell carcinoma (BCC) was the most common malignancy, diagnosed in 183 cases (72\%). BCC/squamous cell carcinoma (SCC) ratio was 3.5. In 39 patients (16.6\%) multiple NMSC were observed.

According to TNM classification most of the NMSC cases were classified as T1 stage (67.7\%). T4 stage was observed in $8.5 \%$ of patients. Lymph node metastases of SCC were noted in 4 patients.

Melanoma was diagnosed in $5.9 \%$ of patients. The average tumor Breslow thickness was $2.83 \pm 2.44 \mathrm{~mm}$ (range: 0.4-6.0 mm). Lymph node metastases were not observed. The head and neck area was the most common tumor site $(75 \%)$.

Exposure to ultraviolet radiation (UVR) connected with work and life style was the most common risk factor, noted in 132 cases (52\%), but cutaneous photoaging symptoms were observed in 168 patients (66.14\%). The coexistence of lesions clinically diagnosed as actinic keratosis was noted in 52 cases (20.5\%). The delay of initiation of treatment was on average about 62 months.

Two hundred and thirteen patients (84\%) suffered from chronic comorbidities, 170 (67\%) more than one. The commonest associated disorders were hypertension (60\%), coronary artery disease (23\%) and diabetes (12\%). In all cases, the surgical risk was assessed using the ASA (American Society of Anesthesiologists) physical status classification system. Most cases (67\%) were classified as ASA 3, the rest as ASA 2 (33\%).

Postoperative medical complications were noted in 10 cases (3.94\%). In 4 patients respiratory system infections, in 1 urinary tract infection, in 4 decompensation of heart failure, and in 1 ischemic stroke were diagnosed. Complications of wound healing were observed in 48 cases (18.9\%) (partial or complete necrosis of lobes or skin transplant). Local recurrences of NMSC were noted in 14 cases (5.51\%). The long-term cosmetic effect was satisfactory. 


\section{Discussion}

Skin cancer is the most frequent malignancy in the Caucasian population. During the last decades an increase of cutaneous malignancies has been shown in various studies $[5,6]$. In the region of Northern Poland that tendency is also noted [4].

During the period from 1998 to 2009, more than 2000 new cases of cutaneous malignancies were diagnosed and treated in the Department of Dermatology, Venereology and Allergology, Medical University of Gdansk [4]. We observed a statistically significant increase of the total number of patients as well as patients over 75 years old.

Our results confirm that UVR is the most important risk factor for skin cancer development. Cumulative and intermittent intense sun exposure was noted in more than half of our patients. Despite the fact that fair skin type (I and II) is recognized as a classic risk factor of developing skin cancer, in our study distribution of skin phototypes was similar to that observed by Chabior [7] in the general Polish population. That fact suggests that total dose of UVR is probably the most important risk factor in developing skin cancer in the elderly population. Personal or family history of skin cancer, which is associated with higher risk of NMSC and melanoma development, was noted in about $8 \%$ of patients.

The histopathological profile of cutaneous malignancies in the elderly differed from our general population (Figure 1) [4]. The BCC/SCC ratio in our general population was 9 [4], and in the present study 3.5. The incidence of SCC was statistically significantly higher compared to our general population (20.5\% vs. $10.9 \%$; $p=0.0002$ ) [4]. These observations confirm literature data that SCC is more often seen in elderly patients [8]. This could be explained by frequent presence of actinic keratosis in these patients. In the present study about $20 \%$ of the patients have clinical symptoms of actinic keratosis. It is estimated that untreated actinic keratosis transforms to SCC in $5 \%$ to $20 \%$ of cas-

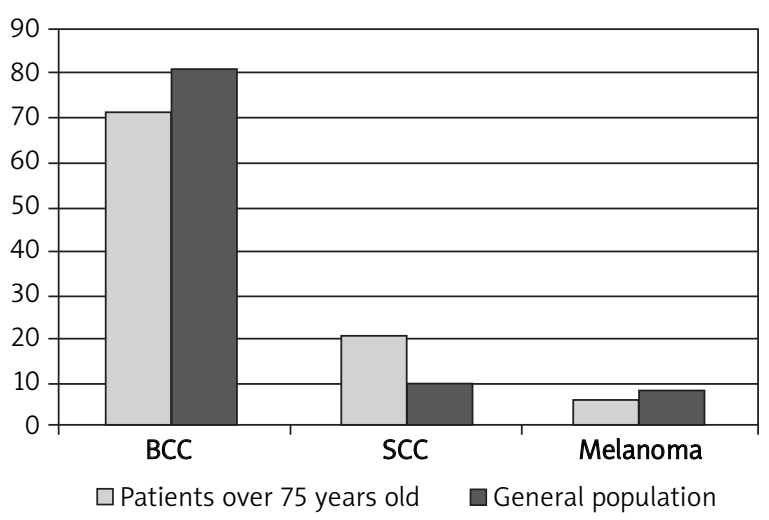

Figure 1. Distribution of BCC, SCC and melanoma in patients over 75 years old compared to general population [4] es during 10-25 years [9]. The BCC/SCC ratio in our material was 3.5 and is similar to the observation by MacFarlane et al. [10] (3.2). Pascual et al. [11] in a retrospective analysis of 52 patients over 90 years old showed SCC in $27.8 \%$ of patients (BCC/SCC ratio 1.8). In a Tunisian study the $\mathrm{BCC} / \mathrm{SCC}$ ratio was almost 3 , but the analysis was based on patients over 65 years old [12]. Taniguchi et al. [8] in a Japanese population observed SCC the most frequently (68\%). These differences are caused by more frequent appearance of SCC in the Asian population and the age of studied cases. In contrast with the literature, our results show that SCC morbidity in the elderly population is higher than in the general population. In elderly patients, treatment of actinic keratosis seems to be important in prevention of SCC. Malignant melanoma was diagnosed in $5.9 \%$ of cases and it was less common than in the whole patient group. The average tumor Breslow thickness was greater than in the general population $(2.83 \mathrm{~mm}$ vs. $1.99 \mathrm{~mm}$ ) (unpublished data).

The head and neck area was the most common tumor site, which is similar to others studies. However, the skin of lower limbs was a statistically more frequent tumor site than in the general population (8.9\% vs. 3.4\%; $p=0.0002)[4]$.

In comparison to our general population, patients over 75 years presented with clinically more advanced melanoma and NMSC [4]. According to the TNM scale, patients over 75 presented more frequent T4 tumors compared to the general population ( $8.5 \%$ vs. $0.8 \% ; p<0.0001)$ (Figure 2). This fact is closely connected with the delay of treatment, which was about 62 months in the study group. In a few cases of very advanced tumors, the authors faced the difficulty of patient's denial of the diagnosis. Despite evidence of the tumor's existence, patients decided not to begin treatment. This phenomenon is observed frequently in oncology and is caused by a psychological defense mechanism - mainly refutation and denial. By these mechanisms patients reduce the stress associated

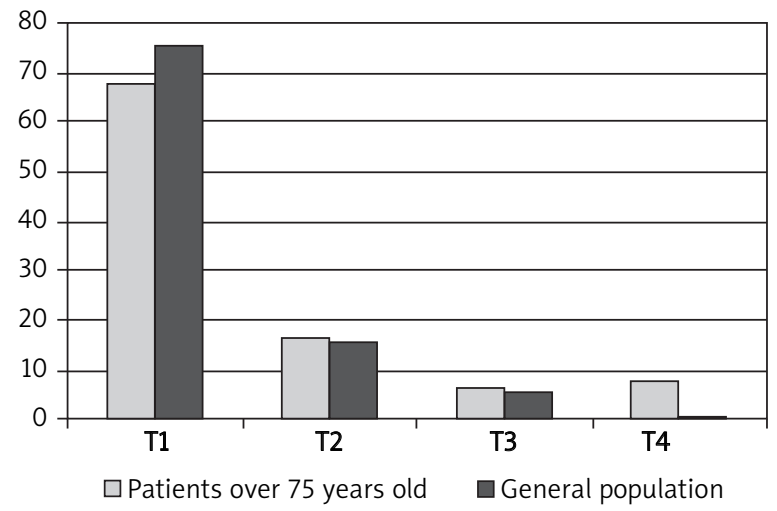

Figure 2. NMSC staging. The incidence of T4 tumor was statistically significantly higher compared to the general population [4] 
with the diagnosis. More frequently, this takes place in elderly, single patients [13].

Nowadays dermatology has a variety of therapeutic methods which can be used in pre-cancers and NMSC treatment [14]. Results of nonablative treatment of "low risk" carcinoma are effective but surgical methods are the choice of treatment in advanced cases [14]. Due to increased morbidity and advanced stages of tumors, elderly patients will have to undergo surgical treatment more frequently. The number of patients operated on in the authors' hospital (254) during nearly 5 years was higher than in the material of Taniguchi et al. [8] during 20 years.

The recurrence rate was higher compared to our general population (5.52\% vs. 3.7\%) but was similar to that noted in patients with high risk tumors (5.52\% vs. 5.2\%). In the Japanese study by Taniguchi et al. the percentage of recurrences was $8 \%$ [8].

The medical complications observed by the authors were incidental and usually in relation to pharmacological non-compliance. Complications of wound healing were relatively common (18.9\%), which may be associated with coexisting diabetes and venous insufficiency.

\section{Conclusions}

The authors observed an increase in morbidity of skin cancer in elderly patients. The clinical and histopathological profile of skin cancer in the elderly differs from the general population. Surgical treatment is safe and effective management in these cases.

\section{References}

1. Greenlee RT, Hill-Harmon MB, Murray T, Thun M. Cancer statistics 2001. CA Cancer J Clin 2001; 51: 15-36.

2. Weinstock MA. The epidemic of squamous cell carcinoma. JAMA 1989; 262: 2138-40.

3. Czerwińska M, Alekseenko A, Rup E, et al. Retrospective data analysis of the history of patients treated for malignant melanoma at the Department of Dermatology, Jagiellonian University between 1991 and 2008. Postep Derm Alergol 2011; 28: 92-6.

4. Włodarkiewicz A, Kozicka D, Michajłowski I, et al. Skin cancer - epidemiological, clinical and surgical treatment analysis of 1406 patients. Przegl Dermatol 2011; 98: 104-11.

5. Lesiak A, Slowik-Rylska M, Rogowski-Tylman M, et al. Risk factors in Central Poland for the development of superficial and nodular basal cell carcinomas. Arch Med Sci 2010; 6: 270-5.

6. Leiter U, Garbe C. Epidemiology of melanoma and nonmelanoma skin cancer - the role of sunlight. Adv Exp Med Biol 2008; 624: 89-103.

7. Chabior A. Usefulness of skin phototype as a parameter of phototoxicity after oral or topical administration of psoralen in patients before PUVA therapy. Przegl Dermatol 2009; 96: 255-63.

8. Taniguchi Y, Shimizu Y, Inachi S, Shimizu M. Skin surgery in patients 90 years of age and over. Int I Dermatol 1998; 37: 547-50.

9. Frost CA, Green AC. Epidemiology of solar keratoses. Br J Dermatol 1994; 131: 455-64.
10. MacFarlane DF, Pustelny BL, Goldberg LH. An assessment of the suitability of Mohs micrographic surgery in patients aged 90 years and older. Dermatol Surg 1997; 23: 389-92.

11. Pascual JC, Belinchón I, Ramos JM, et al. Skin tumors in patients aged 90 years and older. Dermatol Surg 2004; 30: 1017-9.

12. Khaled A, Ben Mbarek L, Zeglaoui F, et al. Epidemiologic study of cutaneous cancers in aged persons. Tunis Med 2008; 86: 895-8.

13. Flynn TC. Denial of ilness: basal cell carcinoma. Dermatol Surg 2004; 30: 1343-4.

14. Telfer NR, Colver GB, Morton CA. British Association of Dermatologists. Guidelines for the management of basal cell carcinoma. Br J Dermatol 2008; 159: 35-48.

15. Witmanowski H, Lewandowicz E, Sobieszek D, et al. Facial skin cancers: general information and an overview of treatment methods. Postep Derm Alergol 2012; 4: 240-55. 